\title{
Physical electrochemistry. Fundamentals, techniques, and applications by Eliezer Gileadi
}

\author{
Wiley-VCH Verlag GmbH \& Co. KGaA, Weinheim, 1st edition (January 14, 2011), \\ 373 pages, $£ 60.00 / € 72.00$, ISBN: $978-3-527-31970-1$
}

\author{
Stephen Fletcher
}

Received: 14 June 2011 / Accepted: 16 June 2011 / Published online: 29 June 2011

(C) Springer-Verlag 2011

In the preface to his new book Physical Electrochemistry, Eliezer Gileadi tells us that his primary motivation was to write a textbook that could form the basis of an introductory course in interfacial electrochemistry. He has succeeded admirably.

Gileadi is a distinguished teacher and researcher, and in this book, he has crystallized his vast experience into 20 self-contained chapters suitable for the beginner. The special value of Gileadi's book is that it answers questions that students actually ask. His cast of mind is always analytical, methodical, and skeptical, and his language is clear and unambiguous.

Where he perceives flaws in the established theory, Gileadi tells us what they are and why they are there. Tacit assumptions are dragged into the daylight, and weak assumptions are ruthlessly exposed. As for false assumptions, they simply do not make it onto the page. The result is a book that is not only trustworthy, but one which also contains what might be termed the irreducible core of physical electrochemistry.

The book provides a fine introduction to electrode kinetics, electrode capacitance, and electrocatalysis. All the classical techniques are described, and special chapters are devoted to electroplating, batteries, and fuel cells. In addition, the various chapters are also self-contained, which means that they can be consulted in sequence, or out of sequence, as the reader prefers. For this reason, the later chapters of the book will also be of use to generalists who wish to develop some specialist knowledge related to the burgeoning new field of materials electrochemistry.

As for omissions, these are few and far between. I was disappointed not to find a section on nucleation and crystal growth, since this underpins a large amount of the electrometallurgical processing industry. But, on reflection, this is probably just a personal gripe. The decision to forego standard referencing is also a little quirky, and may perhaps inhibit weaker students from consulting the original literature. In the context of the total achievement, however, these are very minor complaints. No author is omniscient, and Eliezer Gileadi has crammed more electrochemical knowledge into 373 pages than we have a right to expect. This is an excellent textbook, and I would recommend it to anyone. 